\title{
The contrast of simplicity and accuracy in modeling multi- axial notch fatigue
}

\author{
Christian Riess ${ }^{1, *}$, Martin Obermayr ${ }^{1}$, and Michael Vormwald $^{2}$ \\ ${ }^{1}$ ZF Friedrichshafen AG, 88038 Friedrichshafen, Germany \\ ${ }^{2}$ Materials Mechanics Group, Technische Universität Darmstadt, Franziska-Braun-Straße 3, 64287 \\ Darmstadt, Germany
}

\begin{abstract}
The fatigue assessment of notches under multiaxial and nonproportional service loading is challenging. Simple models (e.g. local strain approach based on normal stress and strain) are of poor quality for this general case of stress states and ductile material behavior. Advanced approaches show high accuracy, but require additional material testing and calibration. From an engineering point of view, deviations are tolerable to a certain extent. This contribution introduces two approaches for modeling multiaxial notch fatigue which are easy to apply. The first approach is an extension of the classical local strain approach. The second approach implements a simplified multiaxial notch approximation which enables the use of the extended short crack model in practical applications.

A large database with experiments on notched components under multiaxial stresses is set up and used to validate the proposed algorithms. Results show the effectiveness of both approaches for ductile steels. Both approaches can be useful for engineers who are faced to multiaxial fatigue of notched components.
\end{abstract}

\section{Introduction}

In spite of the progress over the last decades, the fatigue assessment of notched structures under multiaxial loading is still a challenging task. The main problem for numerical modeling is the simultaneous appearance of multiaxial stresses with rotating principal axes and effects of notches and loading sequence. Relatively simple models, like the local strain concept [1], are widely used in practice. They are user-friendly and don't require many input parameter. In some special applications, e.g. uniaxial stresses or brittle materials, they show good agreement with experimental data. But for the case of multiaxial notch fatigue they lack in accuracy. On the other hand, a lot of research effort has been spent on the mechanisms and modeling of crack initiation and growth under multiaxial and non-proportional stresses [2]. As a result, a highly accurate model for the assessment of multiaxial notch fatigue was developed by Hertel and Vormwald [3, 4].

From a practical point of view, the most important criterion for a model is a general and easy applicability. Drawbacks in accuracy are tolerable to a certain extent. Therefore, within this contribution two approaches for modeling multiaxial notch fatigue are presented. The

\footnotetext{
*e-mail: christian.riess@zf.com
} 
first approach is an extension of the classical local strain concept taking multiaxial, nonproportional and notch effects into account. For the second approach, a simplified multiaxial notch approximation is implemented. In the second approach, fatigue lives are determined on the basis of the extended short crack model $[3,4]$. The aim of this work is to find a good trade-off between simplicity and accuracy. It is out of scope to develop even more complex algorithms to attain higher accuracy.

\section{Previous work}

\subsection{Multiaxial damage parameters}

A countless number of multiaxial fatigue hypotheses have been proposed by researchers during the last decades. These models can be classified into three main groups: Firstly, invariant based parameters (e.g. [5]), secondly, integral damage parameters (e.g. [6]) and thirdly, critical plane approaches (e.g. [7, 8]). The latter ones have gained acceptance and are often implemented in commercial tools. The models in this group differ in the way how normal and shear quantities in the cutting plane are rated. In general, shear based methods are superior at torsional loading, whereas, normal stress and strain based parameters are well-fitting at tension or bending loads. A commonly used normal strain based parameter has been proposed by Smith, Watson and Topper [7]. It is generally accepted that this parameter is a bad choice for ductile materials under torsion. A first approach to scale the normal stress in critical plane was introduced by Gaier and Dannbauer [9]. A similar, but more efficient method was recently proposed by Riess et al. [10]. The multiaxial effect is modeled depending on the current extent of multiaxiality. For the special case of plane stress states, a measure for the degree of multiaxiality is expressed by the biaxiality ratio

$$
h_{\mathrm{biax}}(t)=\frac{\left|\sigma_{x x}(t)+\sigma_{y y}(t)\right|-\sqrt{\left(\sigma_{x x}(t)-\sigma_{y y}(t)\right)^{2}+4 \tau_{x y}^{2}(t)}}{\left|\sigma_{x x}(t)+\sigma_{y y}(t)\right|+\sqrt{\left(\sigma_{x x}(t)-\sigma_{y y}(t)\right)^{2}+4 \tau_{x y}^{2}(t)}},
$$

which can be directly determined from the stress tensor [11]. A material dependent function

$$
f\left(h_{\mathrm{biax}}(t)\right)=1-\frac{1-f_{\mathrm{w}, \tau}}{1-1 / \sqrt{3}} \cdot\left(1-\frac{1}{\sqrt{1+h_{\mathrm{biax}}^{2}(t)-h_{\mathrm{biax}}(t)}}\right)
$$

describes the effect of multiaxial stresses on fatigue lives. A time dependent application of eq. (2) is given in section 3.2.2. This function is the result of a simple interpolation between normal stress hypothesis and distortion energy hypothesis on basis of the shear strength ratio $f_{\mathrm{w}, \tau}=\tau_{\mathrm{w}} / \sigma_{\mathrm{w}}$ [10]. Fig. 1a) shows the application of the proposed multiaxial correction compared to a ductile steel [12] and a brittle cast iron [12].

In contrast to this simple approach of modeling multiaxial effects, the extended short crack model $[3,4]$ is a more advanced alternative. Due to its crack growth based formulation, it is able to account for crack closure induced sequence effects, which makes it superior at multiaxial and variable amplitude loading.

\subsection{Non-proportional hardening}

Rotating principal axes cause an additional hardening which depends on the material and the degree of non-proportionality. Different measures for non-proportionality are known from 
literature: Firstly, transient measures in incremental plasticity (e.g. [13]), secondly, measures that apply on single cycles (e.g. [14]) and thirdly, measures based on entire stress time series (e.g. [15]). Within this contribution, a non-proportionality factor (NPF) from the latter group, which was previously presented in [16], is chosen. It is an improved version of the inertia based NPF proposed by Meggiolaro and Castro [17]. Moments of inertia are evaluated in the Tresca-diagram with respect to the origin

$$
I_{X X}^{\mathrm{o}}=\frac{1}{L} \oint\left(2 \tau_{x y}\right)^{2} \mathrm{~d} p, \quad I_{Y Y}^{\mathrm{o}}=\frac{1}{L} \oint\left(\sigma_{x x}-\sigma_{y y}\right)^{2} \mathrm{~d} p, \quad I_{X Y}^{\mathrm{o}}=-\frac{1}{L} \oint 2 \tau_{x y}\left(\sigma_{x x}-\sigma_{y y}\right) \mathrm{d} p
$$

with the length of the stress path $L$ and the infinitesimal segment $\mathrm{d} p$ [16]. Thereupon, the non-proportionality factor $f_{\mathrm{np}}$ is defined as the root of the ratio of both principal moments of inertia:

$$
f_{\mathrm{np}}=\sqrt{\frac{\lambda_{2}^{\mathrm{o}}}{\lambda_{1}^{\mathrm{o}}}}, \quad \text { with } \quad \lambda_{1,2}^{\mathrm{o}}=\frac{I_{X X}^{\mathrm{o}}+I_{Y Y}^{\mathrm{o}}}{2} \pm \sqrt{\frac{\left(I_{X X}^{\mathrm{o}}-I_{Y Y}^{\mathrm{o}}\right)^{2}}{4}+\left(I_{X Y}^{\mathrm{o}}\right)^{2}} .
$$

A simple approximation [18]

$$
K_{\mathrm{np}}^{\prime}=K^{\prime}\left(1+\alpha f_{\mathrm{np}}\right)
$$

which scales the cyclic hardening coefficient is used to describe the non-proportional hardening effect. A validation for this approximation is given in Fig. 1b) using the plasticity model from Ohno and Wang [19] with $(\alpha=1.0)$ and without $(\alpha=0.0)$ non-proportional hardening correction.
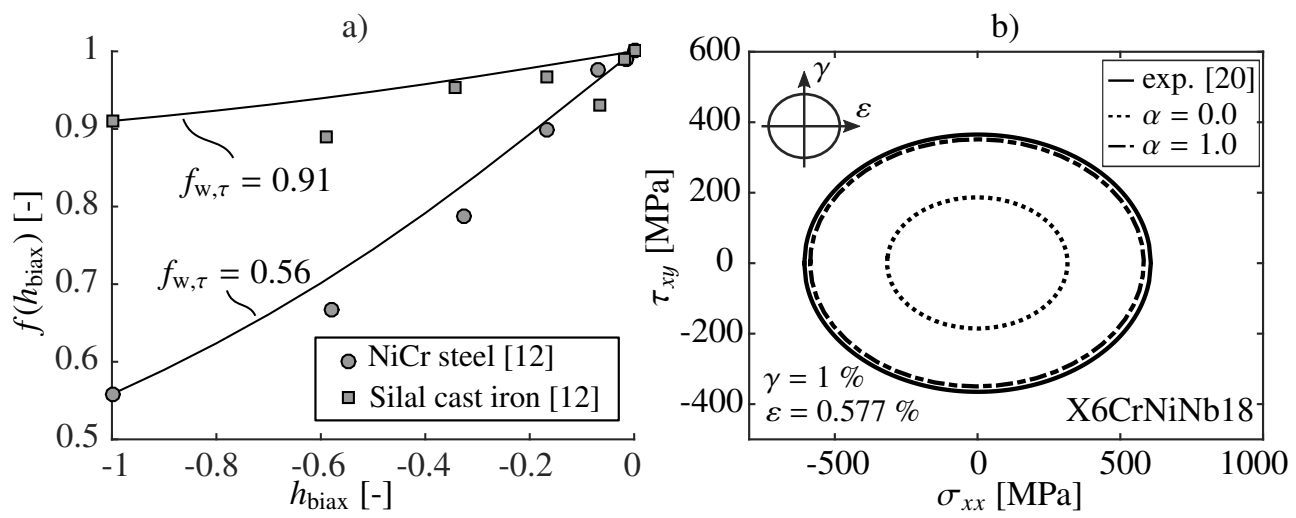

Figure 1. a) Validation of the interpolation function from eq. (2) and b) validation of simplified nonproportional hardening using eq. (5) in an incremental plasticity model (Ohno and Wang [19]).

\subsection{Size effects}

Within this contribution, a stress gradient based approach is chosen to account for size effects and the notch support factor $n_{\sigma}$ is determined by a material dependent transfer function $n_{\sigma}=f\left(\chi, R_{\mathrm{m}}\right)$ [21]. For proportional loading, the normalized gradient $\chi$ is constant and can be easily evaluated using finite element shape functions. For non-proportional loading, the normalized gradient may change over time. In this case, the normalized gradient is evaluated by non-linear superposition of unit load gradients. For more details, please refer to [11]. 


\subsection{Database with notched specimen under multiaxial loading}

A database with notched members under multiaxial loading is implemented in order to validate different calculation approaches. It contains experiments from 9 different steel alloys and 11 notch geometries $\left(1.5<K_{\mathrm{t}}<3.5\right)$ [20, 22-29]. In total 819 data points are available for recalculation. The distribution of the experiments with regard to material type, load sequence and load type can be found in Figure 2. The majority of experiments have number of cycles to failure in the range $10^{4}<N<10^{6}$. A big challenge results from different definitions of failure at different research institutes. In some cases, the failure is defined as a surface crack of 0.5-2 mm, other researchers only record cycles to rupture. This increases the scatter when statistically evaluating the calculation approaches. A uniform failure criterion could help to minimize this scatter caused by different failure criteria.
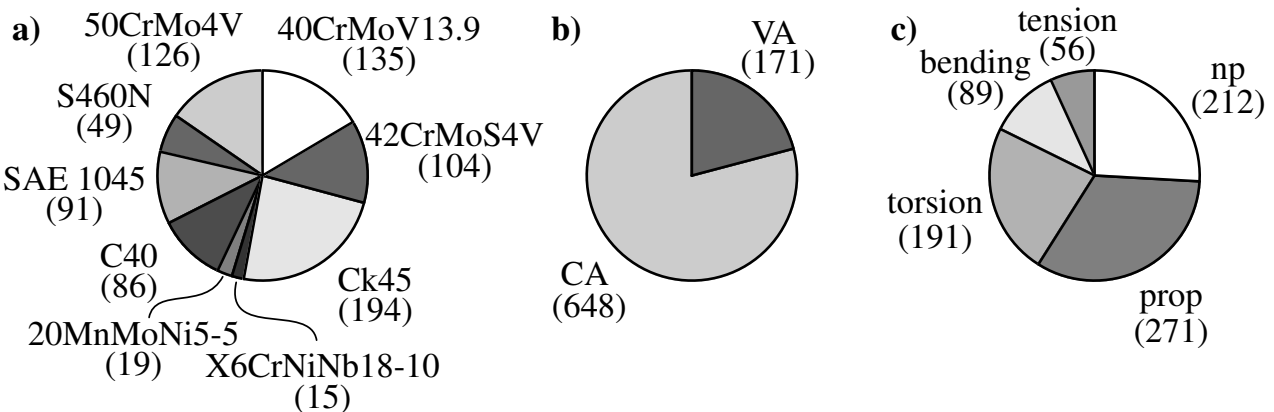

(15)

Figure 2. Distribution of experimental data points in the database regarding a) material type, b) load sequence and c) load type.

\section{Modeling multiaxial notch fatigue}

\subsection{Simplified multiaxial notch approximation and extended short crack model}

A crucial point for many advanced damage models is the determination of notch stresses and strains. Multiaxial notch approximations in combination with advanced plasticity models (e.g. Döring model [30]) yield precise results. However, the determination of model parameters is challenging and requires additional material testing and calibration. Therefore, a simplified multiaxial notch approximation is used within this contribution. It is based on a structural yield surface approach which was introduced by Barkey [31] and refined by Köttgen [32] and Hertel [3, 23? ]. The main differences compared to Hertels approach are: 1. Usage of the plasticity model from Ohno and Wang [19] and 2. simplified non-proportional hardening using eq. (5) to describe the material behavior in the second run of the plasticity model. For more details, please refer to [11]. For this approach, the lifetime to crack initiation is assessed using the extended short crack model $[3,4]$ without further modifications.

\subsection{Modified local strain concept}

A more simplistic approach to determine local stresses and strains is given by uniaxial notch approximations. In combination with a cycle counting method (e.g. HCM), a damage parameter (e.g. $\left.P_{\mathrm{SWT}}\right)$ and a damage accumulation hypothesis, this approach is known as the classical local strain concept. Three modifications are applied to account for non-proportional, multiaxial and size effects. 


\subsubsection{Non-proportional correction}

In a similar way to the previous section, non-proportional hardening is modeled in the second step of the notch approximation. At first, notch strains are determined using the uniaxial material deformation behavior (with $K^{\prime}$ ). Secondly, the corresponding notch stress is determined including non-proportional hardening by using the scaled stress-strain behavior with $K_{\text {np }}^{\prime}$.

\subsubsection{Multiaxial \& size correction}

In practical applications, both the degree of multiaxiality and the stress gradient may change over time. Therefore, a correction on time-step basis is reasonable. Both corrections are applied by scaling the pseudo stress tensor $\sigma^{*}$ prior to the critical plane projection. Accordingly, the time series of pseudo stress in critical plane $\sigma^{*}(t)$ is expressed by

$$
\sigma^{*}(t)=\frac{1}{f\left(h_{\text {biax }}(t)\right) n_{\sigma}(t)}\left[\boldsymbol{\sigma}^{*}(t) \boldsymbol{n}\right] \boldsymbol{n} .
$$

Note that all modifications are simple add-ons to the classical local strain concept and may be easily implemented in existing software.

\section{Results and discussion}

All experimental data points are recalculated using the following three approaches:

A) CPNH: classical local strain concept with normal stress in critical plane and $P_{\mathrm{SWT}}$,

B) CPNH modified: modified local strain concept with proposed non-proportional, multiaxial and size correction,

C) MAX: simplified multiaxial notch approximation and extended short crack model.

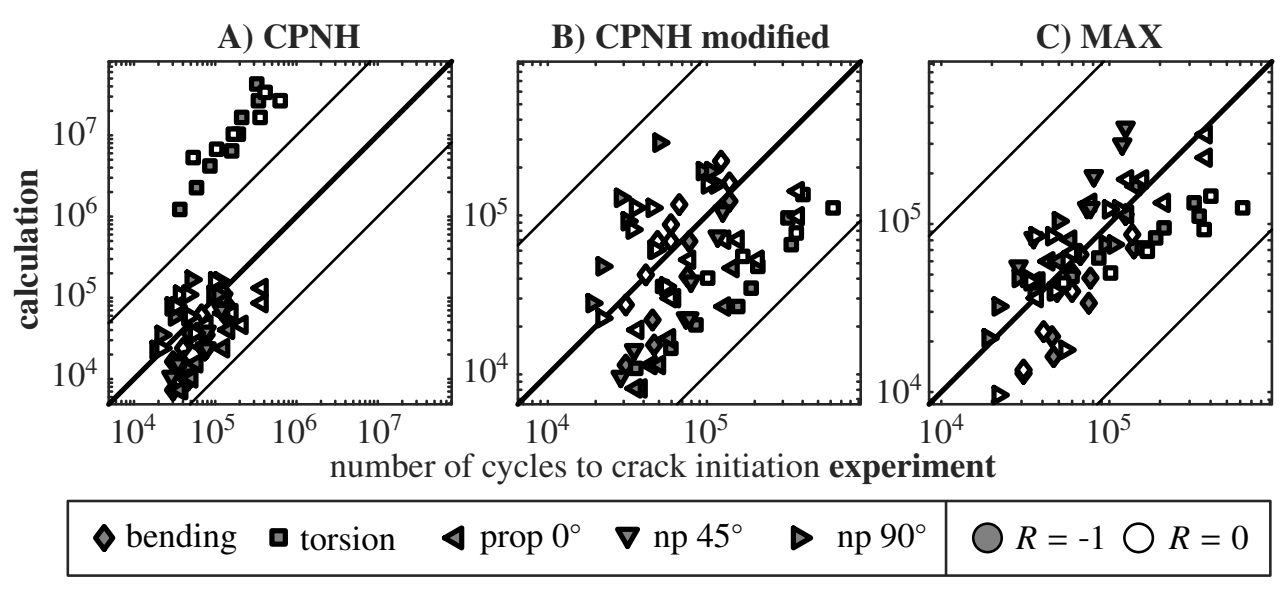

Figure 3. Comparison between experimentally determined and calculated cycles to crack initiation for the steel 50CrMo4V under constant amplitude loading. 


\subsection{CrMo4V CA}

At first, the accuracy of the different approaches is evaluated for the 50CrMo4V [22] data-set with constant amplitude loading. The results in Fig. 3A) clearly show the drawback of the normal stress based approach. Predictions for experiments with torsion loading are highly unsafe. They are located outside of the factor 10 scatter band (thin lines around the bold center-line). The proposed modifications of the normal stress based approach have a beneficial impact on the accuracy of the calculations, see Fig. 3B). All points under torsion loading are moved towards the safe side and are now below the center-line. Best results are attained with the combination of simplified multiaxial notch approximation and extended short crack model, see Fig. 3C). All points are narrowly scattered around the center-line.

A statistical evaluation of these findings is given in Fig. 4 (left). The corresponding scatter values $T_{90 / 10}$ are listed in Table 1, assuming a normal distribution in logarithmic scale. Obviously, the value of 178.6 for the $\mathrm{CPNH}$ approach is too high for practical applications. The modified version with a value of $T_{90 / 10}=9.89$ is a reasonable compromise. The variance of the MAX approach $T_{90 / 10}=4.83$ is almost in the range of materials scatter.

\subsection{CrMo4V VA}

Very similar results are observed under variable amplitude loading, see right side of Fig. 4. Again, the normal stress based approach gives poor results. Modifying the CPNH approach dramatically increases the accuracy (from $T_{90 / 10}=943$ to $T_{90 / 10}=26.5$ ). The lowest scatter value $T_{90 / 10}=12.1$ is attained with the MAX approach. Furthermore, the mean value is close to 1 which is an indication that all effects are modeled qualitatively correct. Note that it is still possible that remaining uncertainties compensate each other and have a beneficial effect. It is striking that the mean value of the modified CPNH approach has a distinct offset $(m=0.39)$. That is not the case for constant amplitude loading, which means that load sequence effects are not modeled properly. This simple approach can only account for mean stress induced sequence effects. Crack closure induced sequence effects are not modeled in SWT-based damage parameters.
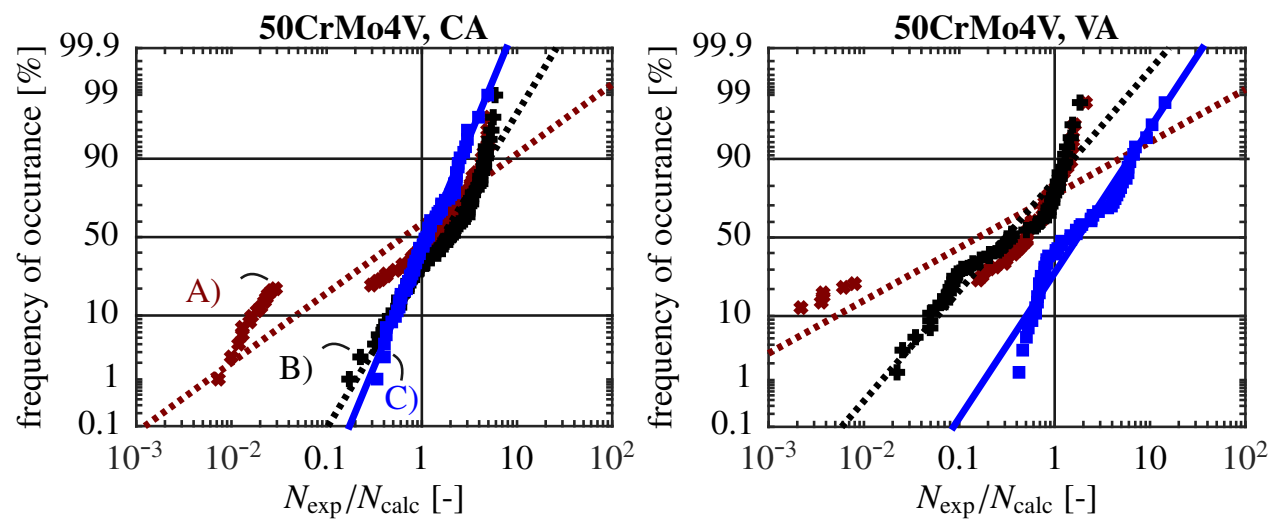

Figure 4. Statistical analysis for the accuracy of the different approaches (data-set 50CrMo4V): A) normal stress in critical plane, B) modified normal stress in critical plane and C) multiaxial notch approximation in combination with short crack model. 


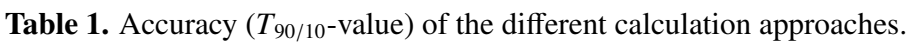

\begin{tabular}{cccc}
\hline$T_{90 / 10}[-]$ & A) CPNH & B) CPNH modified & C) MAX \\
\hline 50CrMo4V, CA & 178.6 & 9.89 & 4.83 \\
50CrMo4V, VA & 943.3 & 26.5 & 12.1 \\
steel, CA & 395.8 & 65.4 & 34.2 \\
steel, VA & 8932 & 94.8 & 18.3 \\
\hline
\end{tabular}

\subsection{Steel CA \& VA}

In a second step, the accuracy is evaluated based on all experiments for the material group steel. Fig. 5 shows the corresponding distributions in a Gaussian probability net. The findings for the data-set 50CrMo4V are confirmed with the whole material group steel, for both constant and variable amplitude loading. In general, the normal stress based approach is a bad choice for ductile materials under multiaxial loading. Better results are attained by applying two simple corrections for multiaxiality and non-proportionality. Best results are determined with the combination of simplified multiaxial notch approximation and extended short crack model. All scatter values $T_{90 / 10}$ are significantly lower. The problem of different failure criteria causes an additional scatter. Therefore, it is difficult to make a qualitative statement or to determine a safety concept based on these data.
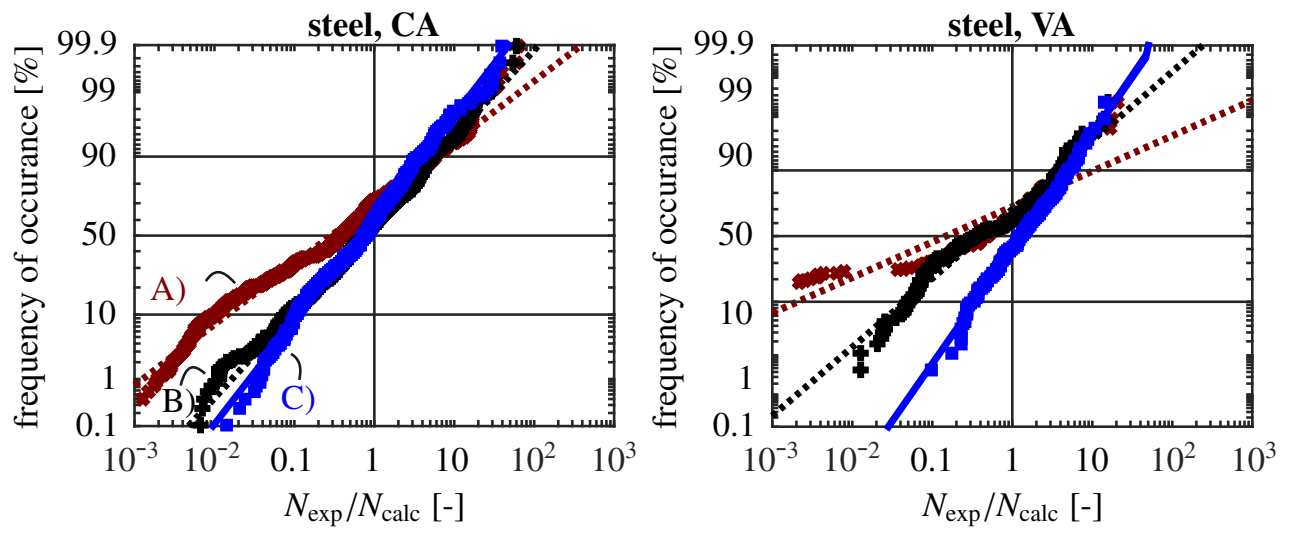

Figure 5. Statistical analysis for the accuracy of the different approaches (materials group steel): A) normal stress in critical plane, B) modified normal stress in critical plane and C) multiaxial notch approximation in combination with short crack model.

\section{Conclusion}

A modified version of the classical local strain concept is proposed which accounts for multiaxial and non-proportional effects. The modifications are a modular add-on to existing algorithms and may be implemented easily in commercial fatigue assessment tools. This approach is a reasonable compromise between simplicity and accuracy. Furthermore, a simplified multiaxial notch approximation is introduced. The non-proportional hardening effect is modeled by adapting the stress-strain behavior on basis of a non-proportionality factor. In combination with the extended short crack model, very accurate results are attained using this 
approach, though the calculation effort is comparably high. A database for validation is very useful to automatically predict fatigue lives with different approaches for a large number of experiments. This enables to compare damage parameters with respect to a general applicability. Future research should not only try to find more complex models with higher accuracy, but also focus on simple models with general applicability.

\section{References}

[1] M. Fiedler, M. Wächter, A. Esderts, M. Vormwald, Richtlinie Nichtlinear [in German] (VDMA Verlag, Frankfurt a.M., 2019)

[2] M. Vormwald, O. Hertel, P. Zerres, Fatigue of engineering structures under combined nonproportional loads: An overview, Fatigue Fract. Eng. M. 41, 1449 (2018)

[3] O. Hertel, M. Vormwald, Short-crack-growth-based fatigue assessment of notched components under multiaxial variable amplitude loading, Eng. Fract. Mech. 78, 1614 (2011)

[4] O. Hertel, M. Vormwald, Multiaxial fatigue assessment based on a short crack growth concept, Theor. Appl. Fract. Mech. 73, 17 (2014)

[5] Z. Hashin, Fatigue failure criteria for combined cyclic stress, Int. J. Fracture 17, 101 (1981)

[6] H. Zenner, A. Simbürger, J. Liu, On the fatigue limit of ductile metals under complex multiaxial loading, Int. J Fatigue 22, 137 (2000)

[7] K.N. Smith, P. Watson, T.H. Topper, A stress-strain function for the fatigue of metals, J. Mater. 5, 767 (1970)

[8] A. Fatemi, D.F. Socie, A critical plane approach to multiaxial fatigue damage including out-of-phase loading, Fatigue Fract. Eng. M. 11, 149 (1988)

[9] C. Gaier, H. Dannbauer, An efficient critical plane method for ductile, semi-ductile and brittle materials, in Proceedings of 9th Int. Fatigue Congress, Atlanta (2006)

[10] C. Riess, W. Hiese, M. Obermayr, M. Vormwald, Engineering approaches to multiaxial and non-proportional fatigue of notched components, Materialwis. Werkst. 49, 381 (2018)

[11] C. Riess, Vereinfachte Ansätze zur Lebensdaueranalyse gekerbter Bauteile unter mehrachsiger und nichtproportionaler Beanspruchung [in German], Ph.D. thesis, IfSW, TU Darmstadt (2019, to be published)

[12] H.J. Gough, Engineering steels under combined cyclic and static stresses, P. I. Mech. Eng. 160, 417 (1949)

[13] E. Tanaka, A nonproportionality parameter and a cyclic viscoplastic constitutive model taking into account amplitude dependences and memory effects of isotropic hardening, Eur. J. Mech. A-Solid 13, 155 (1994)

[14] K. Kanazawa, K.J. Miller, M.W. Brown, Cyclic deformation of 1\% Cr-Mo-V steel under out-of-phase loads, Fatigue Fract. Eng. M. 2, 217 (1979)

[15] J.E. Bishop, Characterizing the non-proportional and out-of-phase extent of tensor paths, Fatigue Fract. Eng. M. 23, 1019 (2000)

[16] C. Riess, M. Obermayr, M. Vormwald, The non-proportionality of local stress paths in engineering applications, Frat. Integ. Strut. 10, 52 (2016)

[17] M.A. Meggiolaro, J.T.P. de Castro, An improved multiaxial rainflow algorithm for non-proportional stress or strain histories - Part I: Enclosing surface methods, Int. J. Fatigue 42, 217 (2012)

[18] D.F. Socie, G.B. Marquis, Multiaxial fatigue (SAE, Warrendale PA, 2000) 
[19] N. Ohno, J.D. Wang, Kinematic hardening rules for simulation of ratchetting behavior, Eur. J. Mech. A-Solid 13, 519 (1994)

[20] J. Hoffmeyer, Anrisslebensdauervorhersage bei mehrachsiger Beanspruchung auf Basis des Kurzrisskonzepts [in German], Ph.D. thesis, IfSW, TU Darmstadt (2005)

[21] R. Rennert, E. Kullig, M. Vormwald, A. Esderts, D. Siegele, Analytical strength assessment 6.th Edition (VDMA Verlag, Frankfurt a.M., 2012)

[22] H. Hanselka, R. Franz, P. Xin, A. Esderts, Mehrachsigkeit [in German] (VDMA Verlag, Frankfurt a.M., 2013)

[23] O. Hertel, Prognose der Anrisslebensdauer gekerbter Bauteile bei mehrachsig nichtproportionaler Betriebsbelastung [in German], Ph.D. thesis, IfSW, TU Darmstadt (2016)

[24] A. Simbürger, Festigkeitsverhalten zäher Werkstoffe bei einer mehrachsigen, phasenverschobenen Schwingbeanspruchung mit körperfesten und veränderlichen Hauptspannungsrichtungen [in German], Ph.D. thesis, Fraunhofer LBF, Darmstadt (1975)

[25] K. Pötter, Lebensdauerabschätzung ein- und mehrachsig schwingend beanspruchter Bauteile [in German], Ph.D. thesis, IMAB, TU Clausthal (2000)

[26] P. Kurath, S.D. Downing, D.R. Galliart, Multiaxial fatigue: Analysis and experiments (SAE, Warrendale PA, 1989)

[27] B. Atzori, F. Berto, P. Lazzarin, M. Quaresimin, Multi-axial fatigue behaviour of a severely notched carbon steel, Int. J. Fatigue 28, 485 (2006)

[28] F. Berto, P. Lazzarin, C. Marangon, Fatigue strength of notched specimens made of 40CrMoV13.9 under multiaxial loading, Mater. Design 54, 57 (2014)

[29] T.M. Fesich, Festigkeitsnachweis und Lebensdauerberechnung bei komplex mehrachsiger Schwingbeanspruchung [in German], Ph.D. thesis, IMWF, Universität Stuttgart (2012)

[30] R. Döring, J. Hoffmeyer, T. Seeger, M. Vormwald, A plasticity model for calculating stress-strain sequences under multiaxial nonproportional cyclic loading, Comp. Mater. Sci. 28, 587 (2003)

[31] M. Barkey, D. Socie, K. Hsia, A yield surface approach to the estimation of notch strains for proportional and nonproportional cyclic loading, J. Eng. Mater. Technol. 116, 173 (1994)

[32] V.B. Köttgen, M.E. Barkey, D.F. Socie, Pseudo stress and pseudo strain based approaches to multiaxial notch analysis, Fatigue Fract. Eng. M. 18, 981 (1995) 